\title{
Annual and Diurnal Variabilities in the Critical Frequency (foF2) during Geomagnetic Fluctuating Activity over Solar Cycles 21 and 22 at Ouagadougou
}

\author{
Abidina Diabaté1, Frédéric Ouattara ${ }^{1}$, Jean Louis Zerbo ${ }^{1,2,3 *}$ \\ ${ }^{1}$ Laboratoire de Recherche en Energétique et Météorologie de l’Espace (LAREME), Université Norbert Zongo, Koudougou, \\ Burkina Faso \\ ${ }^{2}$ Université Nazi Boni, Bobo Dioulasso, Burkina Faso \\ ${ }^{3}$ Laboratoire d'Energies Thermiques Renouvelables (L.E.T.RE), Université Ouaga 1 Pr Joseph Ki-Zerbo, Ouagadougou, \\ Burkina Faso \\ Email: *jeanlouis.zerbo@gmail.com
}

How to cite this paper: Diabaté, A., Ouattara, F. and Zerbo, J.L. (2018) Annual and Diurnal Variabilities in the Critical Frequency (foF2) during Geomagnetic Fluctuating Activity over Solar Cycles 21 and 22 at Ouagadougou. Atmospheric and Climate Sciences, 8, 435-445.

https://doi.org/10.4236/acs.2018.84029

Received: September 14, 2018

Accepted: October 27, 2018

Published: October 30, 2018

Copyright $\odot 2018$ by authors and Scientific Research Publishing Inc. This work is licensed under the Creative Commons Attribution International License (CC BY 4.0).

http://creativecommons.org/licenses/by/4.0/

\begin{abstract}
Geomagnetic activity is characterized by four solar wind conditions. Each condition has specific impact on ionosphere. This paper review on fluctuating activity effects on ionosphere F2 layer through its critical frequency foF2 variations. Under fluctuating wind conditions, we have investigated on annual, diurnal and seasonal variations of foF2 during solar cycles 21 and 22 phases covered by Ouagadougou ionosonde station data (Lat: $12.5^{\circ} \mathrm{N}$; Long: $358.5^{\circ} \mathrm{E}$; dip: $1.43^{\circ}$ ). Our investigations show that foF2 annual' variability is in phase with solar cycle. The diurnal variation is "noon bite out" most of the time except for the solar maximum where we have a morning peak testifying to the fact that the vertical drift $\mathrm{E} \times \mathrm{B}$ is disturbed. The seasonal variations show that the fluctuating activity has no particular effect on certain characteristics of the equatorial ionosphere such as electrojet and vertical drift $\mathrm{E} \times \mathrm{B}$. However, the increase of the electric field pre-reversal phenomenon in autumn is a characteristic effect observed during the fluctuating activity.
\end{abstract}

\section{Keywords}

Critical Frequency, Solar Cycle, Seasonal, Diurnal, Fluctuating Activity

\section{Introduction}

F2-layer of Ionosphere is known to play an important role for radio-commu- 
nication long high frequency (HF). Many studies have reviewed on ionosphere variability in equatorial region; some of them have pointed out the fact that this variability depend on solar cycle, season and geomagnetic activity [1] [2]. This variability is also supposed to be linked with its electric current and electric field which have effect on the critical frequency foF2. Then Analysing ionosphere variability induced investigation on F2-layer's critical frequency (foF2) variability.

Previous studies deal with 1) foF2 time variation during quiet solar activity over season for solar minimum, and high and moderate period 2) foF2 statistical variability over seasons and solar cycle phases and 3) foF2 variability during disturbed periods.

Ouagadougou station, an African sector Equatorial Ionisation Anomaly (EIA) station (Lat: $12.5^{\circ} \mathrm{N}$; Long: $358.5^{\circ} \mathrm{E}$; dip: $1.43^{\circ}$ ) is an interesting position which is able to teach about critical frequency variabilities for equatorial region. For that reason, we focus our present work on data from this station which works from June 1966 to February 1998 and corresponds to three solar cycles (20, 21 and 22). [3] [4] dealing with disturbed conditions do not treat the impact of each type of activity. In this work, we only pay attention to the fluctuating activity' effects in order to investigate on morphological behaviour of equatorial ionosphere during solar cycles phases and seasons for solar cycles 21 and 22. Hopefully, the present study can help to understand the more complex morphology of F2 Layer.

\section{Materials and Methods}

\subsection{Data}

Data in this paper are:

1) F2-layer critical frequency (foF2) hourly values from Ouagadougou (Burkina Faso) ionosonde station data during the solar cycles 21 and 22, provided by Télécom Bretagne;

2) Sunspot numbers Rztaken from: http://spidr.ngdc.noaa.gov/spidr/;

3) Geomagnetic index aa from: http://isgi.unistra.fr/data_download.php and summarized in pixel diagram (Figure 1).

\subsection{Methods}

The diurnal values of foF 2 are obtained with arithmetical calculation for each solar cycle phase and seasons.

Based on the strong correlation between geomagnetic index aa and solar wind velocity established by [5], it is well-known [6]-[12] that disturbed activity is expressed by recurrent activity due to solar high wind stream, shock activity due to Coronal Mass Ejections (CMEs) and fluctuating activity consequences of the fluctuation of solar heliosheet. We used the so-described classification to identified days under fluctuating conditions mean to pixel diagram fully described in [11] [12] [13] and characterized by aa $>20 \mathrm{nT}$. 


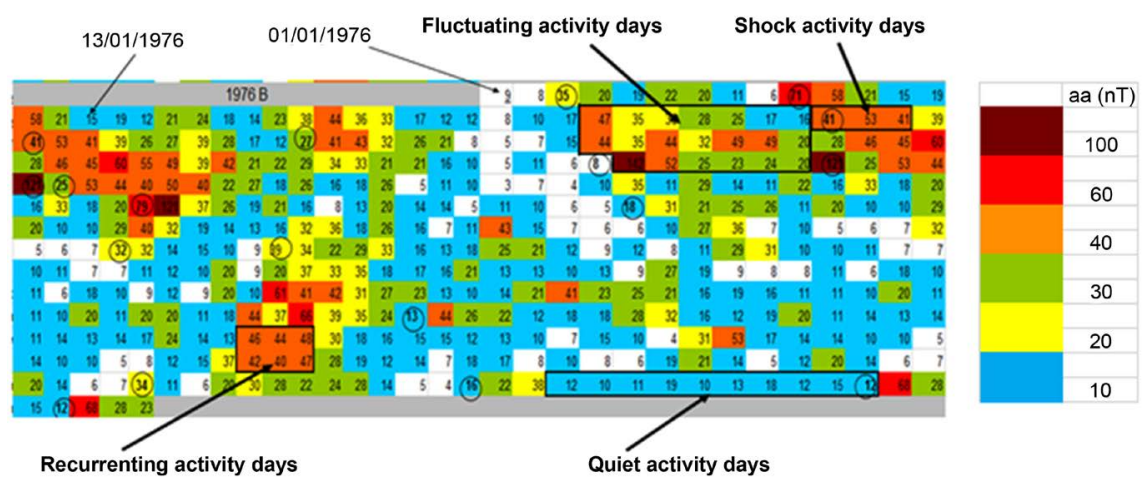

Figure 1. Pixel diagram of year 1976 illustrating geomagnetic activity classes. Each line shows solar rotation, successive lines solar rotations, and each number the daily average of solar wind speed. Circle indicates the date of storm/coronal mass ejection (CME).

The different solar cycle phases (minimum, increasing, maximum and decreasing) are determined following criteria given in [4] [14]: 1) minimum phase: $\mathrm{Rz}<20$, where $\mathrm{Rz}$ is the yearly average Zürich Sunspot number; 2) ascending phase: $20 \leq \mathrm{Rz} \leq 100$ and $\mathrm{Rz}$ greater than the previous year's value; 3 ) maximum phase: $\mathrm{Rz}>100$. For small solar cycles (solar cycles with sunspot number maximum ( $\mathrm{Rz}$ max) less than 100), the maximum phase is obtained by considering $\mathrm{Rz}>0.8 \times \mathrm{Rz}$ max; and 4) descending phase: $100 \geq \mathrm{Rz} \geq 20$ and $\mathrm{Rz}$ less than the previous year's value.

Table 1 gives concerned years for the different phases during the solar cycles 21 and 22.

Seasons are distinguished as follows: Winter (December, January and February); spring (March, April and May); summer (June, July and August) and autumn (September, October and November). Equinoxial periods are spring and autumn and solstice period regroup winter and summer.

The profiles obtained with the data used in this paper are analysed in comparison with different results presented by [15] for African equatorial region: "Dome", "noon bite out", "morning pic", "reversed" and "plateau" profiles. We also inspired ourselves with the works proposed by [16] [17] [18] [19] [20] where it is established the link between these profiles and the nature, strength or absence of electric currents in E layer of ionosphere: "dome" and "plateau" profiles express the absence of electrojet while the "morning pic" profile shows the existence of moderate electrojet; the "reversed" profile shows to the presence of important afternoon conter-electrojet; and the "noon bite out" profile testified to the presence of high electrojet. In addition, [21] [22] [23] reviewed on mechanism responsible of equatorial trough at noon induced by electrodynamics $\mathrm{E} \times \mathrm{B}$ process.

\section{Results}

\subsection{Occurrence of Fluctuating Activity Days}

Using the criteria of the geomagnetic activity classification described in section 
Table 1. Solar cycle phases for cycles 21 and 22.

\begin{tabular}{ccc}
\hline Solar cycle phases & Cycle 21 & Cycle 22 \\
\hline Minimum & 1976 & 1986 \\
increasing & $1977 ; 1978$ & 1987 \\
Maximum & $1979 ; 1980 ; 1981 ; 1982$ & $1988 ; 1989 ; 1990 ; 1991$ \\
decreasing & $1983 ; 1984 ; 1985$ & $1992 ; 1993 ; 1994 ; 1995 ; 1996$ \\
\hline
\end{tabular}

2.2, we have identified 3297 days under fluctuating activity conditions from 1976 to 1996: 1601 days during solar cycle 21 and 1696 days during solar cycle 22. To appreciate the contribution of fluctuating activity, we have evaluated the percentage of occurrence for each phase of solar cycle or each season as followed:

$$
\%=\frac{N_{F} \times 100}{N_{T}}
$$

$N_{F}$ represents the number of fluctuating activity days and $N_{T}$ the total number of days of a considered solar cycle phase or season.

Figure 2 shows the histogram of the percentages of fluctuating activity's occurrence by solar cycle phase (top panels) and by season (bottom panels). We note that for each cycle, fluctuating activity has important occurrences (between $30 \%$ and 50\%) during both cycles. During cycle 21, the occurrence increases from the minimum phase to the decreasing phase while for cycle 22 it fluctuates in "sawtooth pattern". The gap between occurrences per season (bottom panels) is not important. These percentages are in the order of $40 \%$ to $45 \%$ except in the summer of cycle 22 where the percentage is about $38 \%$.

\subsection{Annual Variations of the Critical Frequency foF2}

Figure 3 gives an overview of foF2 behavior during the two solar cycles covered with our data. Two distinct parts can be observed: 1976 to 1985 and 1986 to 1996 corresponding respectively to solar cycles 21 and 22. Both cycles present similar trends: an increasing trend from a minimum value followed by a decreasing trend. The peak in each profile of foF2 is closed to the maximum phase of the given solar cycle. In addition the minimum, increasing and the decreasing in each profile is linked of the minimum, ascending and decreasing phases of solar cycle respectively. We can see that the critical frequency's profile follows the solar cycle evolution.

\subsection{Diurnal Variation by Solar Cycle Phases}

Figure 4 shows the diurnal variation of the critical frequency recorded at the Ouagadougou station during solar cycles 21 and 22 under the fluctuating activity conditions. The continuous curves correspond to the solar cycle 21 and the dotted lines to the solar cycle 22. Data are not available for the cycle 22 .

At the solar minimum phase, we observe a "noon bit out" type profile. The first peak occurs at 09:00 LT and the second at 18:00 LT. The trough is observed 

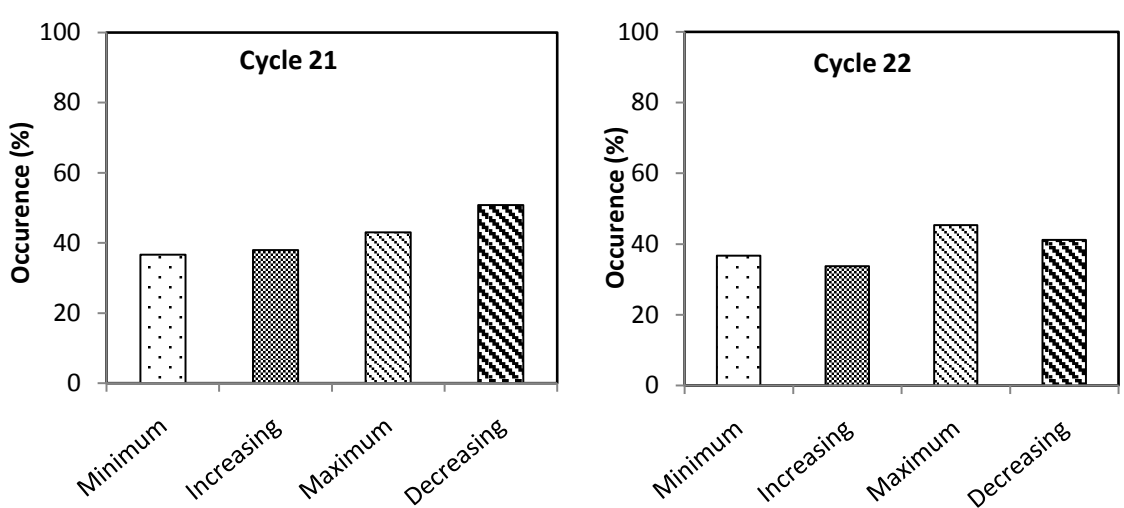

(a)
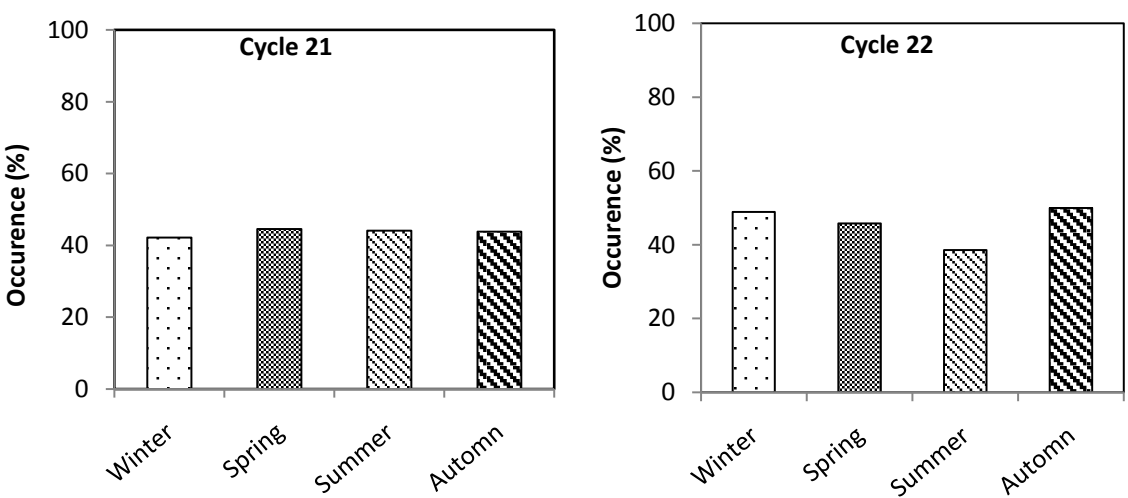

(b)

Figure 2. Occurrence percentage of fluctuating activity days by phase (top panels) and season (bottom panels) during sunspot cycles 21 and 22 .

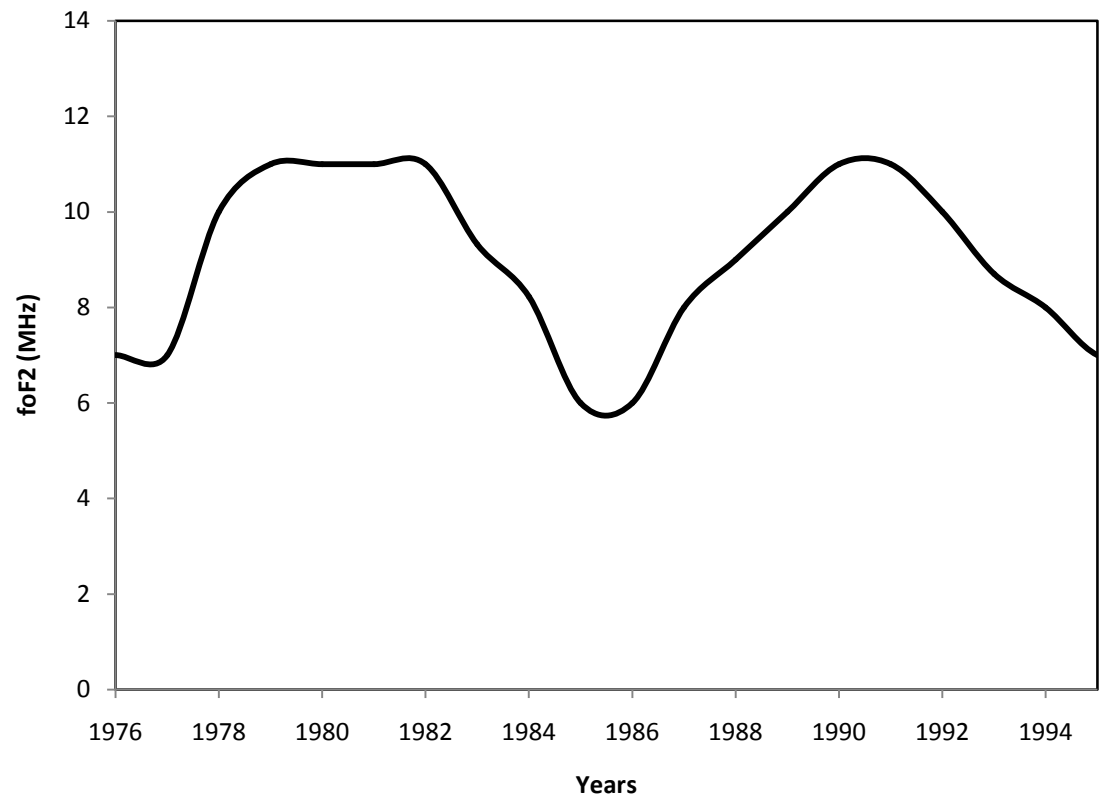

Figure 3. Annual evolution of foF2 during solar cycles 21 and 22.

around 12:00 LT. One can see that the first peak named "morning peak" is more pronounced than the second named "evening peak". 

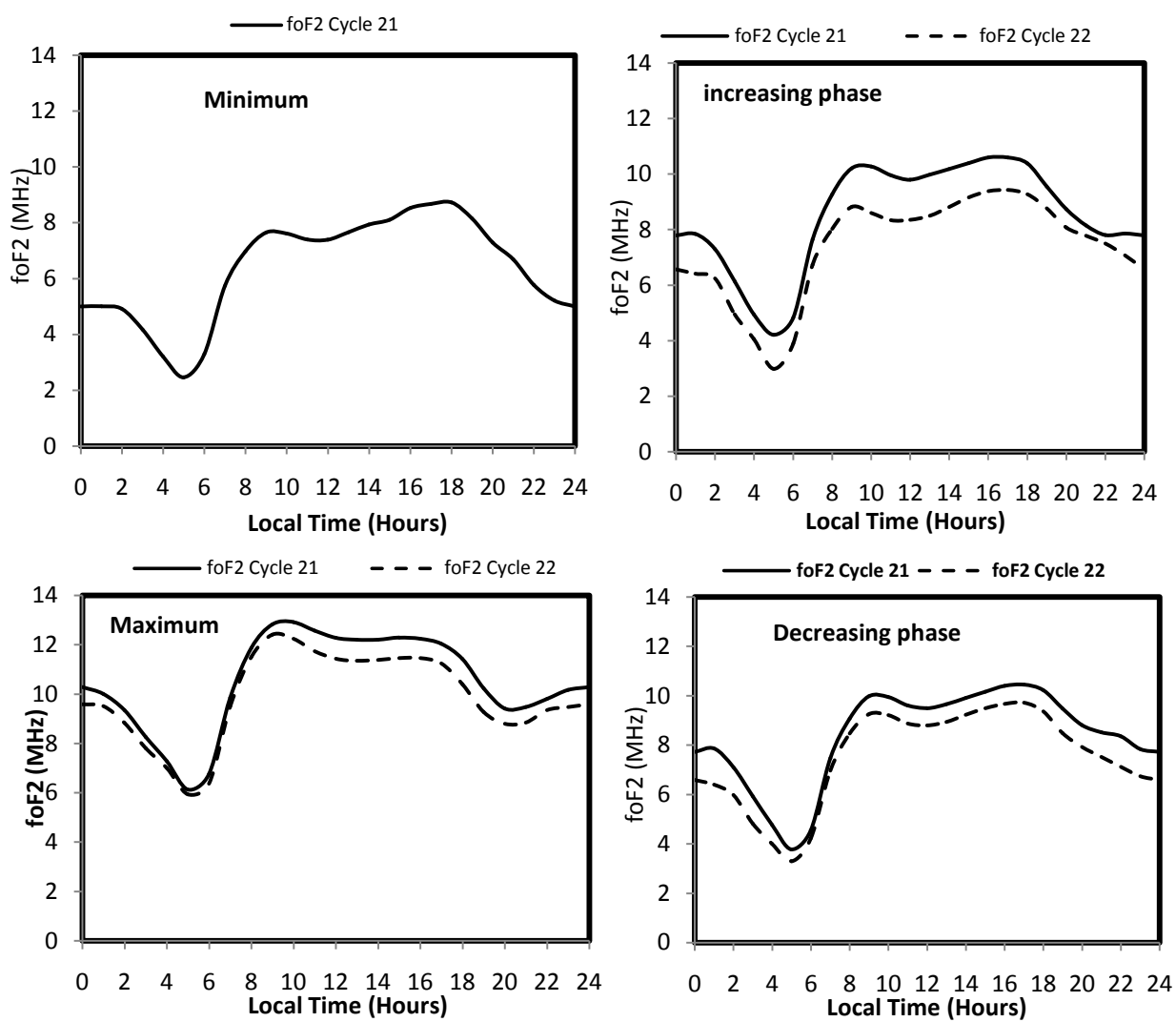

Figure 4. Diurnal variation of the critical frequency foF2 per phase during solar cycles 21 (continuous curve) and 22 (dashed curve).

During the ascending phase we have a "noon bite out" profile. The "morning peak" is observed at 10:00 LT during cycle 21 and at 09:00 LT during cycle 22. The "evening peaks" occur at 16:00 and 17:00 LT respectively at cycle 21 and 22. At solar maxima, we note a "morning peak" profile. The peak occurs at 10:00 LT and at 9:00 for cycles 21 and 22 respectively. Both profiles also present a trough at 20:00 LT followed by a peak around 00:00 LT. One can see that from 09:00 LT each curve shows a decreasing trend.

The decreasing phases are marked by "noon bite out" profiles; the morning and evening peaks occurring respectively at 09:00 LT and 17:00 LT. The midday trough is observed around 12:00 LT for each solar cycle.

It is important to note that for each phase and for each cycle, we have a deep minimum in the morning at 05:00 LT. For our investigation, we can also note that foF 2 profile during cycle 21 is always above that of cycle 22 .

\subsection{Seasonal Diurnal Variation of foF2}

Figure 5 shows the diurnal variations of the critical frequency foF 2 for different seasons during two solar cycles: continuous curves for the cycle 22 and the dotted lines for cycle 22 .

We can remark that all the seasons are characterized by a "noon bite out" profile. 

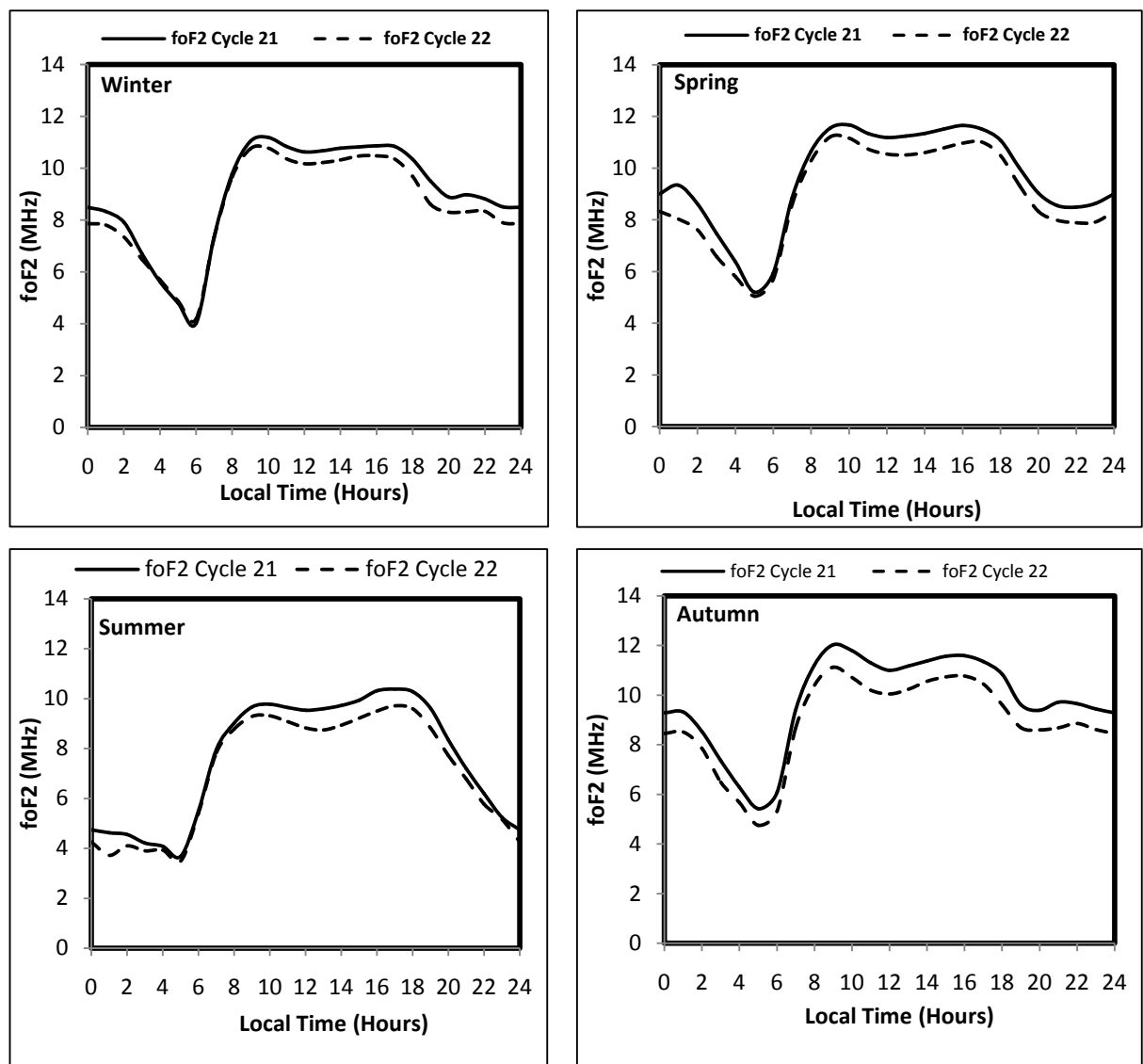

Figure 5. Seasonal diurnal variation of the critical frequency foF2 during solar cycles 21 (continuous curve) and 22 (dashed curve).

During winter the morning peak occurs at 10:00 LT and the evening peak around 17:00 LT. Both peaks are asymmetrical; the morning peak is higher than the evening peak. The midday trough, observed around 12:00 LT is less pronounced.

In spring the peaks are symmetrical. The morning peak occurs at 10:00 LT and the evening peak at 17:00 LT. The trough occurs between 11:00 LT and 14:00 LT.

During summer, the peaks occur respectively at 09:00 LT ant 17:00 LT and the midday trough is observed between 11:00 LT and 16:00 LT. The peaks are asymmetrical; the evening peak is higher than that of the morning.

Peaks are also asymmetrical in autumn; the morning peak (09:00 LT) being more important than the evening one (16:00 LT). The midday trough occurs at 12:00 LT. The autumn profiles present a trough 20:00 LT followed by a peak at 21:00 LT. Autumn is the only season where a night peak is observed.

Winter and summer curves show that the temporal values of foF 2 are higher in winter than in summer. During equinoxes (spring and autumn) the profiles are almost similar and the values almost equal. From sunset (18:00 TL), all the curves decrease but the phenomenon is more important in summer, compared to other seasons. 


\section{Discussion}

The evolution of the annual values of the critical frequency foF2 during the fluctuating activity is a function of the solar cycle phases. During the solar cycle, it increases from the minimum phase to the maximum and decreases from the maximum to the decreasing phase.

foF2 temporal variations over the solar phases show "morning a peak" during each season. In addition, the minimum, increasing and decreasing solar phases are characterized by a "noon bite out" profile. This testifies to the permanent presence of a strong electrojet in the morning. However, the counter-electrojet is only observed during the other solar cycle phases except during the maximum. Except the solar maximum period, the midday trough is observed during the other solar phases. We can deduce that the fluctuating activity disturbs the ascending drift when the solar activity is maximal.

Only the maximum phase is marked by the signature of the pre-reversal enhancement (PRE) of the electric field. The phenomenon is indicated by the night peak during this phase. These observations are in agreement with those made by [22] who noted the presence of increased PRE during the entire solar maximum.

All the seasonal diurnal profiles are "noon bite out" type. The midday trough is observed for all the seasons between 14:00 and 16:00 LT. These two observations show the permanent presence of the electrojet (in the morning) and the counter electrojet (in the evening) and the vertical drift signature during the day. Many authors: [24] [25] [26] [27] showed the seasonal dependence of the vertical drift effect. [28] also noted the effect of drift during all seasons under quiet activity conditions. A comparison with the present observations thus shows that the fluctuating activity has no particular effect on the seasonal properties of the vertical drift $\mathrm{E} \times \mathrm{B}$.

The effect of the pre-reversal of the electric field is observed only during autumn. This pre-reversal phenomenon during autumn is a feature of the effects of fluctuating activity [28].

A simple comparison between the different profiles shows that ionization is more important in winter than in summer. But at the equinoxes the ionization is nearly similar. It can therefore be deduced in agreement that under the fluctuating activity conditions the density of the layer F2 has equinoctial properties.

\section{Conclusions}

This study has investigated on the critical frequency of the F2 layer of the ionosphere (foF2) during fluctuating geomagnetic activity using data from the Ouagadougou ionosonde station for solar cycles 21 and 22. For Annual, diurnal and seasonal variations behaviors of F2-layer interesting results have been pointed out.

1) The annual variation shows that the ionospheric parameter foF 2 evolves according to the solar cycle phases.

2) The temporal variations as a function of the solar activity show the influ- 
ence of the fluctuating activity throughout the pre-reversal of the electric field during the maximum solar phase.

3) The seasonal variations show that the fluctuating activity has no particular effect on certain characteristics of the equatorial ionosphere such as electrojet and vertical drift $\mathrm{E} \times \mathrm{B}$. However, the increase of the electric field pre-reversal phenomenon in autumn is a characteristic effect observed during the fluctuating activity. This study also shows that foF 2 values are higher in winter than in summer; this means an increase in the electron density of the ionosphere in winter compared to summer. At the equinoxes, ionization is almost similar.

\section{Acknowledgements}

The authors thank Brest Telecom for providing Ouagadougou inosonde data and ISGI data centre for providing the aa indices.

Many thanks for ACS editors and anonymous reviewers of this paper.

\section{Conflicts of Interest}

The authors declare no conflicts of interest.

\section{References}

[1] Obrou, K.O. (2008) Contribution à l'amélioration du modèle "International Reference Ionosphere" (IRI) pour l'ionosphère équatoriale". Thèse de Doctorat, Université de Cocody, Abidjan.

[2] Ouattara, F., Amory-Mazaudier, C., Fleury, R., Lassudirie-Duchesne, P. and Vila, P. (2009) foF2 Seasonal Variation per Solar Cycle Phase under Geomagnetic Activities Condition at Ouagadougou. Journal of Atmospheric Solar and Terrestrial Physics.

[3] Ali, M.N., Ouattara, F., Zerbo, J.L., Gyébré, A.M.F., Nanéma, E. and Zougmoré, F. (2015) Statistical Study of foF2 Diurnal Variation at Dakar Station from 1971 to 1996: Effect of Geomagnetic Classes of Activity on Seasonal Variation at Solar Minimum and Maximum. International Journal of Geosciences, 6, 201-208. http://file.scirp.org/pdf/IJG_2015031115312053.pdf https://doi.org/10.4236/ijg.2015.63014

[4] Ouattara, F. and Amory-Mazaudier, C. (2012) Statistical Study of the Diurnal Variation of the Equatorial F-Layer at Ouagadougou from 1966 to 1998. Journal of Space Weather Space Climate, 2, 1-10.

[5] Svalgaard, L. (1977) Geomagnetic Activity: Dependence on Solar Wind Parameters. In: Zirker, J.B., Ed., Coronal Holes and High Speed Wind Streams, Colorado Ass. Univ. Press, Boulder, 371-432.

[6] Legrand, J.P. and Simon, P.A. (1989) Solar Cycle and Geomagnetic Activity: A Review for Geophysicists. Part I. The Contributions to Geomagnetic Activity of Shock Waves and of the Solar Wind. Annales Geophysicae, 7, 565-578.

[7] Simon, P.A. and Legrand, J.P. (1989) Solar Cycle and Geomagnetic Activity: A Review for Geophysicists Part II. The Solar Sources of Geomagnetic Activity and Their Links with Sunspot Cycle Activity. Annales Geophysicae, 7, 579-594.

[8] Richardson, I.G. ,Cliver, E.W. and Cane, H.V. (2000) Sources of Geomagnetic Activity over the Solar Cycle: Relative Importance of Coronal Mass Ejections, HighSpeed Streams, and Slow Solar Wind. Journal of Geophysical Research, 105, 200-213. 
https://doi.org/10.1029/1999JA000400

[9] Richardson, I.G., Cane, H.V. and Cliver, E.W. (2002) Sources of Geomagnetic Activity during Nearly Three Solar Cycles (1972-2000). Journal of. Geophysical Research, 107, 107-118. https://doi.org/10.1029/2001JA000504

[10] Du, Z.L. (2011) The Correlation between Solar and Geomagnetic Activity-Part 2: Long-Term Trends. Annales Geophysicae, 29, 1348. https://doi.org/10.5194/angeo-29-1341-2011

[11] Ouattara, F. and Amory-Mazaudier, C. (2009) Solar-Geomagnetic Activity and Aa Indices toward a Standard. Journal of Atmospheric and Solar-Terrestrial Physics, 71, 1736-1748. https://doi.org/10.1016/j.jastp.2008.05.001

[12] Zerbo, J.L., Amory-Mazaudier, C., Ouattara, F. and Richardson, J. (2012) Solar Wind and Geomagnetism, toward a Standard Classification 1868-2009. Annales Geophysicae, 30, 421-426. https://doi.org/10.5194/angeo-30-421-2012

[13] Zerbo, J.L., Amory-Mazaudier, C. and Ouattara, F. (2013) Geomagnetism during Solar Cycle 23: Characteristics. Journal of Advanced Research, 4, 265-274.

[14] Gnabahou, D.A. and Ouattara, F. (2012) Ionosphere Variability from 1957 to 1981 at Djibouti Station. European Journal of Scientific Research, 73, 382-390.

[15] Faynot, J.M. and Villa, P. (1979) F Region at the Magnetic Equator. Annales Geophysicae, 35, 1-9.

[16] Dunford, E. (1967) The Relationship between the Ionosphere Equatorial Anomaly and the E-Region Current System. Journal of Atmospheric and Terrestrial Physics, 29, 1489-1498. https://doi.org/10.1016/0021-9169(67)90102-X

[17] Vassal, J.A. (1982) Electrojet, contreélectrojet et région F à Sarh (Tchad). Géophysique, ORSTOM, Paris.

[18] Vassal, J. (1982) La variation du champ magnétique et ses relations avec I'électrojetéquatorial au Sénégal Oriental. Annales Geophysicae, 3, 347-355.

[19] Acharya, R., Roy, B., Sivaraman, M.R. and Dasgupta, A. (2010) An Empirical Relation of Daytime Equatorial Total Electron Content with Equatorial Electrojet in the Indian Zone. Journal of Atmospheric and Solar-Terrestrial Physics, 72, 774-780. https://doi.org/10.1016/j.jastp.2010.03.023

[20] Acharya, R., Roy, B., Sivaraman, M.R. and Dasgupta, A. (2011) On Conformity of the EEJ Based Ionospheric Model to the Fountain Effect and Resulting Improvements. Journal of Atmospheric and Solar-Terrestrial Physics, 73, 779-784. https://doi.org/10.1016/j.jastp.2011.01.011

[21] Rishbeth, H. (1971) The F-Layer Dynamo. Planetary and Space Science, 19, 263-267. https://doi.org/10.1016/0032-0633(71)90205-4

[22] Fejer, B.G., Farley, D.T., Woodman, R.T. and Calderon, C. (1979) Dependence of Equatorial F-Region Vertical Drifts on Season and Solar Cycle. Journal of Geophysical Research, 84, 5792-5796. https://doi.org/10.1029/JA084iA10p05792

[23] Fejer, B.G. (1981) The Equatorial Ionospheric Electric Fields: A Review. Journal of Atmospheric and Terrestrial Physics, 43, 377-386. https://doi.org/10.1016/0021-9169(81)90101-X

[24] Richmond, A.D. (1995) Modeling Equatorial Ionospheric Electric Fields. Journal of Atmospheric and Terrestrial Physics, 57, 1103-1115. https://doi.org/10.1016/0021-9169(94)00126-9

[25] Oyekola, O.S. and Oluwafemi, C.C. (2007) Morphology of F-Region Vertical ExB Drifts in the African Sector Using Ionosonde Measurements. Annals of Geophysics, $50,615-625$. 
[26] Adebesin, B.O., Adeniyi, J.O., Adimula, I.A. and Reinisch, B.W. (2013) Equatorial Vertical Plasma Drift Velocities and Electron Densities Inferred from GroundBased Ionosonde Measurements during Low Solar Activity. Journal of Atmospheric and Solar-Terrestrial Physics, 97, 58-64. https://doi.org/10.1016/j.jastp.2013.02.010

[27] Yizengaw, E., Moldwin, M.B., Zesta, E., Biouele, C.M., Damtie, B., Mebrahtu, A., Rabiu, B., Valladares, C.F. and Stoneback, R. (2014) The Longitudinal Variability of Equatorial Electrojet and Vertical Drift Velocityy in the African and American Sectors. Annales Geophysicae, 32, 231-238. https://doi.org/10.5194/angeo-32-231-2014

[28] Ouattara, F., Ali, M.N. and Zougmoré, F. (2015) A Comparative Study of Seasonal and Quiettime fof2 Diurnal Variation at Dakar and Ouagadougou Stations during Solar Minimum and Maximum for Solar Cycles 21-22. European Scientific Journal, 11, 426-435. 